\title{
Deficiência e interseccionalidade: culturas, políticas e práticas educacionais em debate
}

\author{
Disability and intersectionality: cultures, policies and educational practices \\ under debate
}

Discapacidad e interseccionalidad: culturas, políticas y prácticas educativas en discusión

\author{
Carlo Schmidt \\ Professor doutor na Universidade Federal de Santa Maria, Santa Maria, RS, Brasil. \\ Editor-chefe da Revista Educação Especial. \\ E-mail: carlo.schmidt@ufsm.br ORCID: https://orcid.org/0000-0003-1352-9141

\section{Eliana da Costa Pereira de Menezes} \\ Professora doutora na Universidade Federal de Santa Maria, Santa Maria, RS, Brasil. \\ Editora-chefe da Revista Educação Especial. \\ E-mail: elianacpm@hotmail.com ORCID: https://orcid.org/0000-0002-5908-0039
}

\section{Clenio Perlin Berni}

Técnico administrativo em educação na Universidade Federal de Santa Maria, Santa Maria, RS, Brasil.

Editor-gerente da Revista Educação Especial.

E-mail: clenioberni@gmail.com ORCID: https://orcid.org/0000-0002-1267-0357

\section{Mônica Pereira dos Santos (Org.)}

Professora doutora na Universidade Federal do Rio de Janeiro, Rio de Janeiro, RJ, Brasil.

E-mail: monicapes@gmail.com ORCID: https://orcid.org/0000-0002-7057-7804

\section{Jacqueline de Souza Gomes (Org.)}

Professora doutora na Universidade Federal Fluminense, Rio de Janeiro, RJ, Brasil.

E-mail: monicapes@gmail.com ORCID: https://orcid.org/0000-0002-8609-5893

\section{Laura Ceretta Moreira (Org.)}

Professora doutora na Universidade Federal do Paraná, Curitiba, PR, Brasil.

E-mail: laurac.moreira@gmail.com ORCID: https://orcid.org/0000-0003-4569-7369

\section{Editorial}

Identidades são complexas e variáveis ao longo da vida de cada pessoa. A intersecção de identidades, quer relacionada a gênero, etnia, idade, raça, sexo, religião, status socioeconômico ou outros marcadores acentua dificuldades quanto à inclusão de pessoas com deficiência na dinâmica social, especialmente no âmbito educacional. Neste dossiê, exploramos múltiplas experiências de opressão e exclusão, simultâneas ou isoladas, pelas quais passam pessoas com deficiência na sociedade, utilizando a interseccionalidade como ferramenta analítica. Essas formas combinadas de opressão e 
http://dx.doi.org/10.5902/1984686X68899

exclusão são analisadas criticamente em termos de culturas, políticas e práticas de inclusão em educação. Nas palavras de Hill:

\begin{abstract}
O uso da interseccionalidade como ferramenta analítica aponta para várias dimensões importantes do crescimento da desigualdade global. Primeiro, a desigualdade social não se aplica igualmente a mulheres, crianças, pessoas de cor, pessoas com capacidades diferentes, pessoas trans, populações sem documento e grupos indígenas. Em vez de ver as pessoas como uma massa homogênea e indiferenciada de indivíduos, a interseccionalidade fornece estrutura para explicar como categorias de raça, classe, gênero, idade, estatuto de cidadania e outras posicionam as pessoas de maneira diferente no mundo. Alguns grupos são especialmente vulneráveis às mudanças na economia global, enquanto outros se beneficiam desproporcionalmente delas (COLLINS, 2021, p. 33).
\end{abstract}

São 09 (nove) artigos com uma proposta deliberadamente provocativa: a de estimular reflexões sobre as pessoas com deficiência em sua integralidade, considerando-as a partir das várias e complexas dimensões da desigualdade global e local. Pessoas com e para além de suas deficiências. Pessoas marcadas pela diversidade de características que lhes constroem identidades e subjetividades únicas. Objetivamos, pois, provocar reflexões que estimulem a ressignificação da deficiência e do anticapacitismo, ampliados para incluírem outras características que individualizam a experiência identitária de uma pessoa com deficiência. A análise nesta perspectiva de totalidade expõe ainda mais as injustiças, as desigualdades de acesso a direitos e, por consequência, a negação a sistemas, bens e serviços. Reconhecer a deficiência por uma abordagem interseccional enuncia, pois, outras variáveis, positivas e negativas, que atravessam condutas e valores forjados cultural, política e praticamente sobre a deficiência, reforçando como indispensáveis os entrelaces aqui pretendidos entre discursos críticos, como os fundamentados nas teorias de justiça como reconhecimento, nas epistemologias feministas, na perspectiva omnilética, entre outras.

$\mathrm{O}$ artigo "Competencias del professorado para la atención de la diversidade en el aula", de Juan Cornejo-Espejo, é contextualizado no treinamento de professores/as do primário, jardim de infância e ensino médio. Ou seja, pedagogias diferentes cujo foco não gira em torno da atenção de estudantes com NEE. Entretanto, dada a regulamentação existente no Chile, que permite às/aos alunas/os com NEE ou deficiências frequentarem escolas regulares, levanta a questão das competências que esses/as professores/as têm de atender a esses/as alunos/as em escolas regulares sem terem recebido treinamento especial para fazê-lo. O artigo também discute as noções de inclusão mantidas por esses/as professores/as (muito limitadas, a propósito), que tendem a associar a inclusão 
quase exclusivamente ao SEN. Eles/as também mostram pouca receptividade para pensar em inclusão a partir de uma perspectiva intersetorial, ou seja, pensar nos/as estudantes com NEE como tendo outras identidades (raça, gênero, etc.), o que às vezes pode ser outro motivo de exclusão.

Em "La sobrerrepresentación de los estudiantes pertenecientes a minorías culturales y lingüísticas en itinerarios de educación especial: una revisión de la literatura en Europa", as autoras Marta Sandoval Mena e Maria Antonietta Chieppa, revisam a literatura europeia para identificar a abordagem teórica e metodológica da representação excessiva de estudantes de minorias culturais e linguísticas rotulados/as pelas administrações educacionais como estudantes com deficiências ou Necessidades Educacionais Especiais. As questões giram em torno de como o fenômeno da interseccionalidade tem sido abordado em estudantes de minorias culturais e linguísticas na Europa e sua ligação com a super-representação nas categorias de Necessidades Educacionais Especiais associadas à deficiência. As publicações analisadas foram classificadas em quatro abordagens teóricas: a) organização escolar e desempenho acadêmico dos/as estudantes; b) preconceito profissional; c) procedimentos de diagnóstico e rotulagem; e d) desigualdades estruturais: procedimentos institucionais históricos, culturais e sociais. Uma das principais conclusões das autoras é que há uma mudança na maneira como a pesquisa sobre representação excessiva aborda a questão.

Blanca Estela Zardel Jacobo, no artigo "El carácter de interpelación de la "Discapacidad": política y prácticas emergentes", analisa o caráter político da "deficiência", referindo-se não à relação binária implícita de poder entre aquele que domina e o dominado, ou aquele que tem poder e aquele que é submetido; mas a política será considerada como aponta Hannah Arendt: como o que é produzido na inter-relação do "estar junto", e que "estar junto" afeta a exterioridade, mobiliza, questiona e torna possível a transformação das dimensões sociais e impacta os sentidos e significados de uma realidade, produzindo um horizonte de possíveis aberturas que mudam a visão do mundo imediato. Este caráter de "estar juntos" nas múltiplas e diversas práticas sociais emergentes de pessoas com "deficiências" produz em suas afetações imediatas de exterioridade que subvertem o sentido de deficiência pelas diferentes formas de ser e estar no mundo.

Sabe-se que, dentre os grupos minoritários, o das pessoas com deficiência é o mais numeroso no mundo. Sabe-se, igualmente, que dentre a população de refugiados, cerca de 7 a 10\% são pessoas com deficiência (NOGUEIRA, 2019). Estes dados garantiriam às 
http://dx.doi.org/10.5902/1984686X68899

pessoas com deficiência um forte marcador identitário enquanto tal, assim como um status de grande representatividade perante outras minorias. Contudo, não é assim que a realidade concreta se mostra. Dados do Relatório das Nações Unidas para Refugiados Tendências Globais, de 2019, apontam que 52\% da população de refugiados do mundo é de mulheres e que elas estão entre os mais vulneráveis entre todos os refugiados no mundo. Quadro que piora muito mais, se as mulheres refugiadas tiverem deficiência. Neste sentido, o artigo "Com deficiência, mulher e refugiada: uma tríade omnileticamente interseccional", de Mônica Pereira dos Santos e Mylene Cristina Santiago, discute esta interseccionalidade à luz da perspectiva omnilética, revelando e desvelando o interjogo entre culturas, políticas e práticas, dialética e complexamente presentes neste quadro interseccional.

$\mathrm{O}$ artigo "O crescer bilíngue de Codas: memórias da infância na passagem pela escola", de Ricardo Ernani Sander e Sandra Eli Sartoreto de Oliveira Martins, identifica as marcas da identidade/subjetividade de filhos ouvintes de pais surdos - Codas, como sujeito(s) bilíngue(s), na infância. Trata-se de um recorte dos enunciados produzidos no encontro do pesquisador, com quatro Codas, em uma pesquisa de doutorado, mais ampla. À luz dos estudos bakhinianos, a materialidade da apreensão do objeto de análise perfila sobre a formação do ser Codas pela alteridade, na fronteira de duas línguas e culturas de prestígio social diferentes em suas memórias da/na escola. Todavia os contornos identitários circunscrevem enunciados de um "mundo precoce adulto" que incide sobre a infância, fora dos muros escolares. Tais aspectos convocam os/as profissionais da educação a refletirem sentidos outros, no cronotopo das experiências dos/as que se reconhecerem ou não ouvintes, na visualidade da língua de sinais com seus pais surdos.

Contradições e opressões "invisibilizadas" pulsam se atentamos à situação das mulheres com deficiência e das mães de pessoas com deficiência no sistema prisional brasileiro. O contexto prisional reproduz uma sociedade sexista, patricarcal e conservadora, excluindo as especificidades que compõem o universo das mulheres, seja em relação à orientação sexual, raça, idade, deficiência, maternagem, nacionalidade, entre outros. À luz da justiça como reconhecimento, o artigo "Deficiência, reconhecimento e (in)justiça: apontamentos sobre a situação de mulheres com deficiência encarceradas e encarceradas mães de pessoas com deficiência no Brasil”, de Jacqueline de Souza Gomes, faz apontamentos sobre como o negligenciamento da diversidade de experiências de reconhecimento violam identidades e negam direitos básicos às mulheres com 
http://dx.doi.org/10.5902/1984686X68899

deficiência encarceradas. O objetivo foi investigar se há ausência de reconhecimento destas mulheres expressa pela precariedade de dados, estudos e indicadores, a ocultar, por consequência, violações no acesso à direitos básicos destas e de sua prole. Enquadrar a situação destas mulheres em termos de justiça como reconhecimento reverbera, ainda, o caráter relacional da justiça e, a partir daí, reforça uma necessária discussão sobre a estruturação do nosso ethos social, que nos faz capacitistas e legitimadores(as) de uma sociedade que pune pessoas pelo que são, não pelo que fazem.

Silvia Regina Vieira da Silva e Eliana Marques Zanata, no artigo "Perspectiva inclusiva no contexto do ensino de engenharia e tecnologia", apresentam os resultados de uma pesquisa de abordagem qualitativa, tendo como objeto de estudo os anais do Congresso Brasileiro de Educação em Engenharia (COBENGE) dos últimos cinco anos. Este evento está relacionado à Associação Brasileira de Educação em Engenharia (ABENGE), que ocorre desde 1973 com periodicidade anual e visa promover a melhoria do ensino de graduação e pós-graduação em engenharia e tecnologia no Brasil. Tal escolha fundamentou-se em experiências profissionais e na literatura e o objetivo foi verificar quais as possíveis discussões sobre inclusão existiam na área da Engenharia, considerada, por alguns, como "ciência dura". Foi utilizada a palavra inclusão como descritor e os resultados indicaram que o processo de inclusão, alvo de diversas pesquisas na área de Ciências Humanas, também está presente na área de Ciências Exatas, em uma associação relacionada ao ensino, destacando-se a inclusão de pessoas com deficiência física e sensorial, transtorno do espectro autista e minorias até certa época na invisibilidade.

Por fim, o dossiê traz o artigo "Crianças e adolescentes com deficiência em situação de violência: cruzamento de conectores sociais", de Laura Ceretta Moreira e Fabiola Rodrigues Del Mouro, que trata das vulnerabilidades e exclusões vivenciadas por crianças e adolescentes com deficiência, apontando o quanto essa população está submetida a situações de violência, sobretudo, a intrafamiliar. A precariedade de estudos entre a interseccionalidade deficiência e violência e seus conectores sociais, a fragilidade das políticas públicas para o enfrentamento dessa problemática são discutidas no presente estudo. O lócus do estudo ocorre em dois municípios paranaenses, entre 2015-2020, a partir das informações em sítios públicos e em relatórios institucionais da Secretaria Municipal de Assistência Social e do Conselho Tutelar. Os dados mapearam situações de agressões e maus-tratos e permitiram a análise cruzada das categorias: violência sofrida, deficiência declarada, escolaridade, gênero, raça-cor, idade e situação econômica das 
famílias. As visões discriminatórias, o preconceito, a precária rede de apoio às famílias e de formação aos profissionais da saúde e da educação, também são abordados no estudo. Desejamos uma ótima leitura!

\section{Referências}

COLLINS, P. H. Interseccionalidade. São Paulo: Boitempo, 2021.

NOGUEIRA, A. J. A. N. Pessoas com Deficiências Refugiadas: indesejáveis e invisíveis. Brazil Journal of Development, v. 5, n. 10, 2019. Disponivel em: https://www.brazilianjournals.com/index.php/BRJD/article/view/3599. Acesso em: 20 Dezembro 2021.

(c) (1) (9) International (CC BY-NC 4.0) 